\title{
Long-Term Relapse Outcomes of Smoking Cessation in Older Smokers
}

\author{
๑ Didem Gorgun Hattatoglu, ๑ Birsen Pinar Yildiz \\ University of Health Sciences Turkey, Yedikule Chest Disease and Surgery Training and Research Hospital, Clinic of Pulmonology, \\ Istanbul, Turkey
}

\section{Abstract}

Aim: Limited data are available in the literature about the long-term results of smoking cessation and the relapse rate in older smokers. We aimed to demonstrate the efficacy of short- and long-term smoking cessation behaviors in individuals over 65 years of age.

Methods: Patients' data were analyzed retrospectively from hospital records between 2014 and 2018. All patients received individual behavioral therapy and were prescribed the drugs that were best suited for their individual circumstances, such as nicotine replacement therapy, bupropion, and varenicline. Patients who quit smoking during the three-month period of outpatient follow-up were contacted by phone at least two years later and asked whether they still smoked or not.

Results: In total, 68 older participants (13 female and 56 male) were included. In the initial three-month follow-up period, 29 of the participants (42.6\%) dropped out of the smoking cessation program after the first interview. Eleven of the smokers (16.2\%) did not quit smoking, and $28(41.1 \%)$ did quit smoking. Fourteen participants $(20.6 \%)$ achieved long-term abstinence (i.e., were not smoking at the two-year follow-up), while the remaining 10 participants (14.7\%) had started to smoke again. No statistically significant difference was found between quitters and non-quitters in terms of age, gender, duration of the smoking habit, the number of cigarettes smoked daily, the reason for starting smoking, the reason for the desire to quit smoking, and the treatment methods used.

Conclusion: Smoking cessation strategies should be tailored and constantly re-evaluated in elderly people for safe management, and they should be followed up closely to avoid relapse risk.

Keywords: Aged, smoking cessation, recurrence

\section{Introduction}

The rate of using tobacco and tobacco products among people aged 65 and older in Turkey is $17.9 \%$ for men and $2.6 \%$ for women (1). It is known that smoking is associated with an increased risk of chronic heart and lung diseases, cerebrovascular diseases, and cancer, and these diseases are most prominent in the aged population. Thus, increased risk of morbidity and mortality attributed to tobacco exposure can be prevented through smoking cessation. In the elderly population, mortality is approximately three-fold greater among smokers, while a decreased mortality risk with smoking cessation has been found, despite the high mortality rates in this age group (2). Mortality rates are lower in former smokers who have abstained longer, suggesting that the best results are achieved when people stop smoking early. It was observed that male smokers who quit at age 65 gained 1.4 to 2.0 years of life expectancy, and women gained 2.7 to 3.7 years of life expectancy. Additionally, the health benefits of smoking cessation that have been demonstrated for older adult smokers include a lower risk of stroke, respiratory tract disease, and cancer. Thus, quitting smoking even at an older age can yield substantial benefits (3).

It has been determined that the results of smoking cessation behavioral therapy and pharmacotherapy are as effective in the elderly as in the young $(4,5)$. However, limited data are available in the literature about the longterm results of smoking cessation and the relapse rate in older smokers. In this study, we aimed to demonstrate the short- and long-term efficacy of smoking cessation behaviors in individuals over 65 years of age.

Address for Correspondence: Didem Gorgun Hattatoglu, University of Health Sciences Turkey, Yedikule Chest Disease and Surgery Training and Research Hospital, Clinic of Pulmonology, Istanbul, Turkey E-mail: didem_gorgun@yahoo.com ORCID: orcid.org/0000-0001-7067-9360 Received: 07.05.2021 Accepted: 14.08.2021 


\section{Methods}

\section{Data Collection}

Our study was approved by the local ethics committee University of Health Sciences Turkey, Istanbul Training and Research Hospital Ethics Committee (date: 08.05.2020, no: 2264). Owing to the retrospective nature of the study with no available informed consent.

In total, 68 older participants ( 13 female and 56 male) were included in our study from among 550 patients who applied voluntarily to the smoking cessation clinic at Yedikule Chest Diseases and Chest Surgery Training and Research Hospital, Istanbul, Turkey between January 2014 and September 2018. Patients' data were analyzed retrospectively and they were contacted by phone and asked whether they were smoking or not in January 2020.

Participants' demographic information was recorded, and they completed the six-item Fagerström test for nicotine dependence test at the first visit to the smoking cessation program. A score of 5 or more indicates significant dependence, while a score of 4 or less shows a low to moderate dependence (6). All patients received individual behavioral therapy and were prescribed the drugs that were best suited for their individual circumstances, such as nicotine replacement therapy (NRT), bupropion, and varenicline.

Participants who smoked $\geq 20$ cigarettes daily received $21 \mathrm{mg}$ nicotine/24 h nicotine patches for four weeks, followed by patches with a reduced dose (14 mg nicotine/24 h) for two weeks, and then by patches with a further reduced dose (7 $\mathrm{mg}$ nicotine/24 h) for two more weeks. For individuals who smoked $<20$ cigarettes daily, we offered $14 \mathrm{mg}$ nicotine $/ 24 \mathrm{~h}$ patches for six weeks followed by $7 \mathrm{mg}$ nicotine/ $24 \mathrm{~h}$ patches for two weeks.

Participants were given either bupropion $150 \mathrm{mg} /$ day for the first three days and $300 \mathrm{mg} /$ day for 12 weeks from the fourth day or varenicline $0.5 \mathrm{mg} /$ day from the first to the third day, $1 \mathrm{mg} /$ day on the fourth to the seventh day, and $2 \mathrm{mg} /$ day from the second to the $12^{\text {th }}$ week. All participants were encouraged to revisit the clinic every 1-2 weeks after the first session. Combined therapies were provided to patients who were not successful with their first treatment or their medications were changed at follow-up visits.

Besides the pharmacological treatment, all patients received individual behavioral therapy from a physician and a smoking cessation nurse. Non-quitters included participants who did not provide follow-up data or were lost to follow-up and those who failed to quit smoking. Patients who quit smoking during the three-month period of outpatient follow-up were contacted by phone at least two years later and asked whether they still smoked or not.

\section{Statistical Analysis}

The data were analyzed using IBM SPSS Statistics $18^{\circ}$ SPSS Inc. The compliance of continuous variables with normal distribution was examined with the KolmogorovSmirnov test. Categorical variables are presented as frequency and percentage, and continuous variables as mean, standard deviation, median, and the smallest and largest values. Associations between categorical values were calculated by chi-square tests and Fisher's Exact tests. Significant differences between groups for parametric continuous values were determined with the Student's t-test, while the Mann-Whitney $U$ test was used for non-parametric continuous variables. A p-value of 0.05 was considered significant.

\section{Results}

A total of 68 participants (13 female and 55 male; mean age $67.35 \pm 3.04$ years) were included in the study. The demographic variables are shown in Table 1.

Although $28(41.1 \%)$ of the smokers were able to quit smoking in the first three months following the smoking

\begin{tabular}{|c|c|c|c|}
\hline & Quitter ( $n=14)$ & $\begin{array}{l}\text { Non-quitter } \\
(n=54)\end{array}$ & p \\
\hline Age (mean \pm SD) & $68.07 \pm 3.56$ & $67.16 \pm 2.95$ & $0.41^{\pi}$ \\
\hline Weight (kg) & $68.21 \pm 11.71$ & $67.16 \pm 2.95$ & $0.15^{\pi}$ \\
\hline $\begin{array}{l}\text { Gender } \mathbf{n}(\%) \\
\text { Female } \\
\text { Male }\end{array}$ & $\begin{array}{l}1(7.7 \%) \\
13(23.6 \%)\end{array}$ & $\begin{array}{l}12(92.3 \%) \\
42(76.4 \%)\end{array}$ & $0.20^{* *}$ \\
\hline $\begin{array}{l}\text { Marital status n (\%) } \\
\text { Married } \\
\text { Single } \\
\text { Widow }\end{array}$ & $\begin{array}{l}12(22.2 \%) \\
0(0.0 \%) \\
2(15.4 \%)\end{array}$ & $\begin{array}{l}42(77.8 \%) \\
1(100.0 \%) \\
11(84.6 \%)\end{array}$ & $0.75^{* *}$ \\
\hline $\begin{array}{l}\text { Children n (\%) } \\
\text { Yes } \\
\text { No }\end{array}$ & $\begin{array}{l}13(21.0 \%) \\
1(50.0 \%)\end{array}$ & $\begin{array}{l}49(79.0 \%) \\
1(50.0 \%)\end{array}$ & $0.91^{* *}$ \\
\hline $\begin{array}{l}\text { Educational level n (\%) } \\
\text { Primary school } \\
\text { Juniour high school } \\
\text { High school } \\
\text { University }\end{array}$ & $\begin{array}{l}9(18.8 \%) \\
4(36.4 \%) \\
0(0.0 \%) \\
1(50.0 \%)\end{array}$ & $\begin{array}{l}39(81.2 \%) \\
7(63.6 \%) \\
7(100.0 \%) \\
1(50.0 \%)\end{array}$ & $0.20^{*} *$ \\
\hline $\begin{array}{l}\text { Job n (\%) } \\
\text { Non-working } \\
\text { Active working } \\
\text { Retired }\end{array}$ & $\begin{array}{l}1(9.1 \%) \\
0(0.0 \%) \\
13(24.1 \%)\end{array}$ & $\begin{array}{l}10(90.9 \%) \\
3(100.0 \%) \\
41(75.9 \%)\end{array}$ & $0.35^{* *}$ \\
\hline $\begin{array}{l}\text { Comorbidities n (\%) } \\
\text { Cardiovascular diseases } \\
\text { Cerebrovascular diseases } \\
\text { COPD } \\
\text { Malignancy } \\
\text { Liver diseases } \\
\text { Depresion } \\
\text { Alcohol consumption }\end{array}$ & $\begin{array}{l}5(35.7 \%) \\
0(0.0 \%) \\
5(35.7 \%) \\
2(14.3 \%) \\
0(0.0 \%) \\
0(0.0 \%) \\
0(0.0 \%)\end{array}$ & $\begin{array}{l}14(25.9 \%) \\
3(5.6 \%) \\
9(16.7 \%) \\
4(7.4 \%) \\
1(1.9 \%) \\
3(4.4 \%) \\
2(3.7 \%)\end{array}$ & $\begin{array}{l}0.69 * * * \\
0.86 \\
0.23 \\
0.78 \\
0.60 \\
0.86 \\
0.46\end{array}$ \\
\hline
\end{tabular}

*Row percentage, ${ }^{*}{ }^{*}$ Column percentage, $"$ t-test, ${ }^{\mu}$ Mann-Whitney $U$ test, ${ }^{*}$ Chisquare test, COPD: Chronic obstructive pulmonary disease, SD: Standard deviation 
cessation intervention, only 14 achieved long-term abstinence (20.6\%) after two years, while the remaining $10(14.7 \%)$ had started to smoke again (Figure 1). The smoking cessation rate was $7.7 \%$ for women and $23.6 \%$ for men.

Participants' smoking history and cessation behaviors are shown in Table 2.

Participants' reasons for their intention to quit smoking included current illness (55.8\%), doctor's advice (47\%), fear of illness $(45.5 \%)$, social pressure $(30.8 \%)$, harm to the environment $(29.4 \%)$, desire to be a good example for their family $(29.4 \%)$, disturbance of smell $(25 \%)$, shame (13.2\%), economic concerns (10.2\%), religious beliefs $(7.3 \%)$, and workplace pressure (1.47\%). No significant difference was observed in terms of their reasons for starting smoking or for their desire to quit smoking and their smoking cessation behavior ( $p>0.05)$.

Eight $(18.1 \%)$ of the 44 participants who applied to the smoking cessation program voluntarily quit smoking, while $26.1 \%$ of the 23 participants who applied to the program on the advice of a doctor quit smoking.

Treatment methods and relationships showed Graphic 1 for quitters and non-quitters. No significant relationship was observed between the treatment methods used and smoking cessation results ( $p>0.05$ ) (Graphic 1).

The most common side effects of NRT were dry mouth, attention deficit, dyspepsia, palpitations, and anorexia. Of the patients who used bupropion, 15 (46.6\%) had dry mouth, four (26.6\%) experienced itching, and four $(26.6 \%)$ had insomnia. Among the patients who used varenicline, nine $(26.4 \%)$ experienced dry mouth, eight $(23.5 \%)$ reported colorful dreams, eight had (23.5\%)

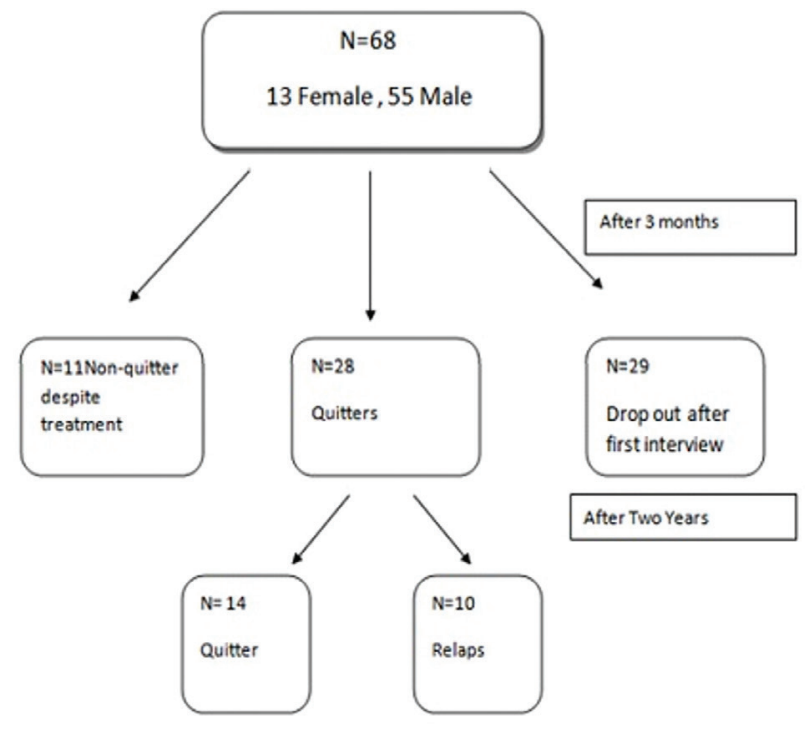

Figure 1. Scatter diagram of participants insomnia, five (14.7\%) experienced nausea, and five (14.7\%) experienced personality change.

Seven of these participants had started smoking again in the first three to six months following the smoking cessation program, one of them relapsed 18 months after the program, and one of them started smoking in the third year after the program. No statistically significant difference was found between quitters and those who restarted smoking in terms of age, gender, duration of smoking, the number of cigarettes smoked daily, the reason for starting smoking, the reason for the desire to quit smoking, and the treatment methods used.

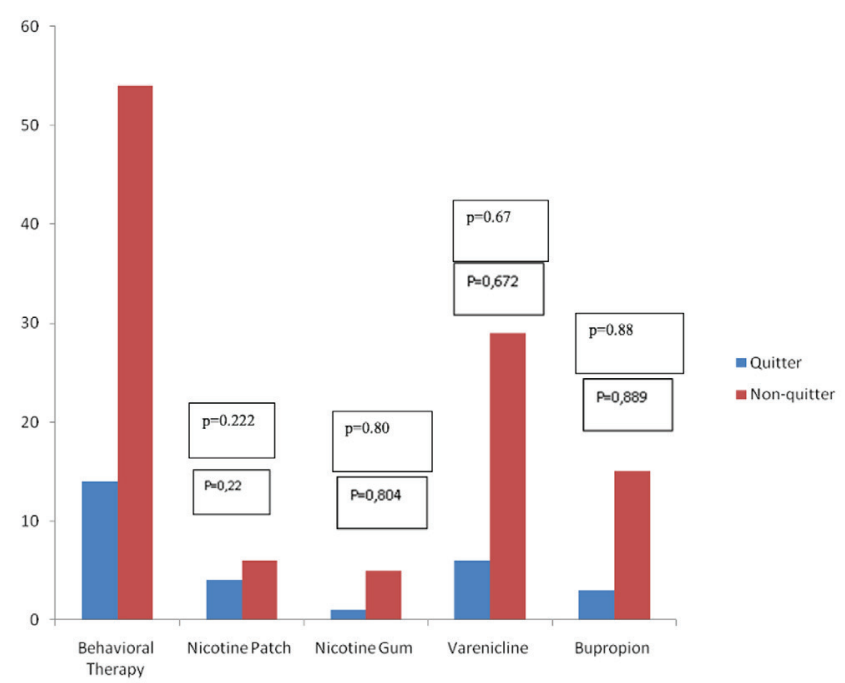

Graphic 1. The relationship between treatment methods used and smoking cessation behavior

\begin{tabular}{|l|l|l|l|}
\hline \multicolumn{4}{|c|}{ Table 2. Smoking history and cessation behavior of participants } \\
\hline & $\begin{array}{l}\text { Quitter } \\
(\mathbf{n = 1 4 )}\end{array}$ & $\begin{array}{l}\text { Non-quitter } \\
(\mathbf{n}=\mathbf{5 4})\end{array}$ & $\mathbf{p}$ \\
\hline Smoking duration & $46.93 \pm 8.59$ & $44.02 \pm 8.74$ & 0.27 \\
\hline Daily amount of cigarette & $21.36 \pm 10.94$ & $27.80 \pm 19.06$ & 0.15 \\
\hline Number of attemps to quit & $3.07 \pm 2.64$ & $2.20 \pm 4.20$ & 0.06 \\
\hline $\begin{array}{l}\text { Fagerstrom nicotine } \\
\text { dependence }\end{array}$ & $5.36 \pm 2.27$ & $5.24 \pm 2.67$ & 0.77 \\
\hline t-test & & \multicolumn{3}{|l}{} \\
\hline
\end{tabular}

\section{Discussion}

In our study, the quit rate at three-month following a smoking cessation program for individuals over 65 years of age was $41.1 \%$, but at the two-year long-term followup, 10 patients had started smoking again, and thus, the long-term quit rate was $20 \%$.

Both short- and long-term smoking cessation rates in the elderly are at least as high as in younger people (7). In a study conducted in Brazil, the cessation rate was 
reported as $41.1 \%$ in elderly participants, while $35.4 \%$ of participants younger than 60 years old were smoke-free at a one-year long-term follow-up. In a Taiwan cohort, the rate of short-term smoking cessation at a three-month follow-up was $48.1 \%$; the long-term results of this study have not been reported $(8,9)$. Moreover, the smoking cessation rate of older smokers was found to be $37.3 \%$ at a three-year follow-up in another study (10). In our study, the drop-out rate after the first interview conducted as part of the smoking cessation program was $42 \%$; this is compatible with the results of previous studies that included participants of all ages. Previous results indicated that older age smokers had lower dropout rates compared with younger smokers (11). In a previous study conducted in our clinic, the quit rate after six months was found to be $24 \%$ for all ages, but long-term data was not available (12). Our present data showed that older smokers can quit smoking at almost the same rate as the general population as indicated by our historic controls. Considering the long-term results (i.e., two-year follow-up), older smokers seem to be less successful according to our results, but this needs more clarification due to the limited data in the literature. Some studies have demonstrated that older people quit smoking at a higher rate than younger adults $(13,14)$. Kim et al. (4) showed that the rate of quitting smoking in the elderly was two-fold higher than in their younger counterparts. This may be related to the absence of comorbid diseases associated with smoking in younger age groups. However, although elderly smokers are more likely to succeed in quitting than their younger counterparts, attempting a smoking cessation program could be more challenging for elderly people (13). The motivation to quit in the elderly might be low due to several reasons, but success rates are higher once they are admitted to a program. Our cohort of smokers aged $>65$ years demonstrated an acceptable quit rate both in the short and long term.

Studies have indicated that more chronic illness, being a nondrinker, being married to a non-smoking spouse, living in a household with no other smokers, having smoked for a shorter duration, consuming more cigarettes daily, experiencing depression, being more educated could be predictors of smoking cessation among the elderly $(4,15)$. However, our study, similar to previous studies, showed that all the socio-demographic variables studied as well as smoking duration, the number of pack-years, nicotine dependence and comorbidities were not significantly correlated with quitting smoking (16). Several studies have suggested that compared to men, women may be at greater risk for smoking-related diseases and may also have greater difficulty quitting smoking, which may result from a combination of biological, psychological, and social factors along with reduced access to smoking cessation treatment $(17,18)$. Whitson et al. (16) reported higher rates of quitting in females, while other studies have demonstrated that males were more successful (17). In our study, no statistically significant difference was found between women and men.

Previous studies have found that elderly patients most frequently want to quit smoking due to existing illness or fear of illness $(10,19)$. In our study, the factors that most often motivated attempts to quit smoking were similar to previous data. However, it is noteworthy that sensitivity to environmental harm and a desire to be a good example for their family seems to be prominent motivators in Turkish society, and this could be associated with the cultural and social characteristics of the population. In fact, Gunay et al. (14) found the thought of harming the environment was the most common reason for quitting smoking. Older Turkish smokers were also motivated to succeed in smoking cessation to provide a better role model for their children and grandchildren (14). It is also known that advice and encouragement from doctors and other healthcare professionals increase the motivation to quit smoking, and that older smokers are more sensitive to doctors' advice $(20,21)$. In our study, it was seen that those who applied to the smoking cessation program under the advice of a doctor had a higher rate of quitting in both the short and the long term. Therefore, doctors should ask their elderly patients whether they smoke or not, regardless of their complaint, and elderly patients should be advised by their doctor to quit smoking.

In our study, no difference was observed between the treatment methods in terms of smoking cessation success either at the three-month (short-term) or two-year (long-term) follow-up. In the literature, some studies have found that pharmacotherapy increases smoking cessation success up to four-fold. Behavioral therapy might play an additive role in increasing quit rates (22). In some studies, NRT alone was significantly more effective or equally effective as varenicline and bupropion and would be safe for older smokers $(9,23)$. However, the effectiveness of treatment strategies for smoking cessation in the elderly is controversial. Recently published a real world cohort study, effectiviness of cessation strategies were not superior than unassisted quitting (7). We obtained reasonable results with a $20 \%$ long-term quit rate at the two-year follow-up in older smokers; the choice of treatment had no impact on the quit rate. During our follow-up, no side effects that could cause serious mortality or morbidity were observed. While the most common side effects were dry mouth in all groups, colorful dreams and insomnia were observed frequently in varenicline users without any need for drug cessation. Generally, pharmacotherapy for smoking cessation can be used safely in the elderly; however, 
specific metabolic characteristics, comorbidities, and multiple medicines use should be taken into consideration (24). Therefore smoking cessation strategies should be tailored and constantly re-evaluated in elderly patients for safe management.

Few studies have explored the limits of recidivism in older smokers by providing long-term follow-up data. A detailed analysis of factors that contribute to recidivism and the development of protocols associated with reducing the relapse rate in elderly people would enhance the success of smoking cessation programs. It is known that the rate of resumption of smoking is $35-40 \%$ for all ages in one year, but few studies have been conducted specifically on the elderly $(10,25,26)$. In two cohort studies, the resumption of smoking rate was reported as $1 \%$ and $16 \%$, respectively. Both studies provide longitudinal follow-up results without any data on treatment effect and the results are given cross-sectionally (16). Pekel et al. (26) found a relapse rate of $50.1 \%$ for all ages without any specific analysis of the elderly population and nicotine dependency was shown to be associated with higher rates of relapse; this is similar to the results of previous studies (27). Esen et al. (28) found relapse in males (12.9\%) was significantly lower than in females $(20.9 \%)$ and no significant difference in relapsing between the mean age groups. In our study, the recidivism rate was 35.7\%; no association was found between recidivism and age, gender, duration of smoking, the number of cigarettes smoked per day, the reason for starting smoking, the reason for quitting, and the treatment methods. In previous studies, neither behavioral treatments nor bupropion nor NRT prevented relapses. However, varenicline decreased the rate of relapse (29). In our study, those who resumed smoking most often started again within six months. Therefore, it can be concluded that older patients should be followed periodically for at least six months or a year to avoid relapse risk.

\section{Study Limitations}

Our study has some limitations. First, we intentionally prescribed the drugs that were best suited for each participants' individual circumstances. This would create bias in comparing the effect of different medications on smoking cessation success. Second, data on our long-term abstinence rate was collected by phone and based on patient self-reports, which were not confirmed biochemically. Therefore, participants may have misreported whether they quit smoking or not. Finally, our sample size was relatively small, and further large studies are needed to confirm our results. Although this cohort has a limited number of participants, it may contribute to the literature due to the limited data evaluating long-term relapse outcomes in the elderly.

\section{Conclusion}

Smoking cessation increases the quality of life by reducing mortality and morbidity in the elderly as well as in all ages. Older smokers are willing to quit smoking as much as young adults and they are successful at least young counterparts. All elderly patients should be questioned about their smoking status, regardless of their complaints, and directed to a smoking cessation programme for appropriate treatment by physicians. Tailored cessation programs and drugs should be program according to their metabolic characteristics, comorbidities, and medication use. It is also extremely important to follow up, question whether they smoke or not and motivate successful quitters regularly to avoid recidivism.

\section{Authorship Contributions}

Concept: D.G.H., Design: D.G.H., B.P.Y., Data Collection or Processing: D.G.H., Analysis or Interpretation: D.G.H., Literature Search: D.G.H., Writing: D.G.H., B.P.Y.

Conflict of Interest: No conflict of interest was declared by the authors.

Financial Disclosure: The authors declared that this study received no financial support.

\section{References}

1. Turkey Statistics Institute (TUIK). Turkey Statistical Institute Global Adult Tobacco Survey. Turkey Statistical Institute Newsletter [Internet] Available from: http://www.tuik.gov.tr/ PreHaberBultenleri. Accessed: 05.12.2012

2. Nash SH, Liao LM, Harris TB, Freedman ND. Cigarette Smoking and Mortality in Adults Aged 70 Years and Older: Results From the NIH-AARP Cohort. Am J Prev Med 2017;52:276-83.

3. Tessier JF, Nejjari C, Letenneur L, Barberger-Gateau P, Dartigues JF, Salamon R. Smoking and eight-year mortality in anelderly cohort. Int J Tuberc Lung Dis 2000;4:698-704.

4. Kim SK, Park JH, Lee JJ, et al. Smoking in elderly Koreans: prevalence and factors associated with smoking cessation. Arch Gerontol Geriatr 2013;56:214-9.

5. Lugo A, La Vecchia C, Boccia S, Murisic B, Gallus S. Patterns of smoking prevalence among the elderly in Europe. Int J Environ Res Public Health 2013;10:4418-31.

6. Ebbert JO, Patten CA, Schroeder DR. The Fagerström Test for Nicotine Dependence-Smokeless Tobacco (FTND-ST). Addict Behav 2006;31:1716-21.

7. Watkins SL, Thrul J, Max W, Ling PM. Real-World Effectiveness of Smoking Cessation Strategies for Young and Older Adults: Findings From a Nationally Representative Cohort. Nicotine Tob Res 2020;22:1560-8.

8. Chang $\mathrm{CP}$, Huang WH, You CH, Hwang LC, Lu IJ, Chan HL. Factors Correlated with Smoking Cessation Success in Older 
Adults: A Retrospective Cohort Study in Taiwan. Int J Environ Res Public Health 2019;16:3462.

9. Scholz J, Santos PC, Buzo CG, et al. Effects of aging on the effectiveness of smoking cessation medication. Oncotarget 2016;7:30032-6.

10. Hsu CL, Hsueh KC, Chou MY, et al. Long-term smoking cessation rates in elderly versus other adult smokers: A 3-year follow-up study in Taiwan. Addict Behav Rep 2018;8:62-5.

11. Bahadir A, Iliaz S, Yurt S, Ortakoylu MG, Bakan ND, Yazar E. Factors affecting dropout in the smoking cessation outpatient clinic. Chron Respir Dis 2016;13:155-61.

12. Önür ST, Uysal MA, Iliaz S, et al. Does Short Message Service Increase Adherence to Smoking Cessation Clinic Appointments and Quitting Smoking? Balkan Med J 2016;33:525-531.

13. Steinberg MB, Akincigil A, Delnevo CD, Crystal S, Carson JL. Gender and age disparities for smoking-cessation treatment. Am J Prev Med 2006;30:405-12.

14. Gunay T, Pekel O, Simsek $H$, et al. Smoking habits and cessation success. What differs among adults and elderly? Saudi Med J 2014;35:585-91.

15. Abdullah AS, Ho LM, Kwan YH, Cheung WL, McGhee SM, Chan WH. Promoting smoking cessation among the elderly: what are the predictors of intention to quit and successful quitting? J Aging Health 2006;18:552-64.

16. Whitson HE, Heflin MT, Burchett BM. Patterns and predictors of smoking cessation in an elderly cohort. J Am Geriatr Soc 2006;54:466-71.

17. Mackay J, Amos A. Women and tobacco. Respirology 2003;8:123-30.

18. Romeo-Stuppy K, Huber L, Lambert P, et al. Women, tobacco, and human rights. Tob Induc Dis 2021;19:48.

19. Twardella D, Loew M, Rothenbacher D, Stegmaier C, Ziegler $\mathrm{H}$, Brenner $\mathrm{H}$. The diagnosis of a smoking-related disease is a prominent trigger for smoking cessation in a retrospective cohort study. J Clin Epidemiol 2006;59:82-9.
20. He T, Liu L, Huang J, Li G, Guo X. Health Knowledge about Smoking, Role of Doctors, and Self-Perceived Health: A CrossSectional Study on Smokers' Intentions to Quit. Int J Environ Res Public Health 2021;18:3629.

21. Ossip-Klein DJ, Mclntosh S, Utman C, Burton K, Spada J, Guido J. Smokers ages 50+: who gets physician advice to quit? Prev Med 2000;31:364-9.

22. Chang PY, Shiu MN, Yuan YT, Chang HC, Su PY, Lan TH. Comparative Effectiveness of Varenicline and Nicotine Replacement Therapy for Smoking Cessation in Older and Younger Smokers: A Prospective Cohort in Taiwan. Nicotine Tob Res 2019;21:149-55.

23. Burstein $A H$, Fullerton $T$, Clark DJ, Faessel HM. Pharmacokinetics, safety, and tolerability after single and multiple oral doses of varenicline in elderly smokers. J Clin Pharmacol 2006;46:1234-40.

24. Molander L, Hansson A, Lunell E. Pharmacodynamics of nicotine in healthy elderly people. Clin Pharmacol Ther 2001;69:57-65.

25. Hajek P, Stead LF, West R, Jarvis M. Relapse prevention interventions for smoking cessation. Cochrane Database Syst Rev 2005:CD003999.

26. Pekel Ö, Ergör G, Günay T, et al. Smoking Cessation and the Effect of Nicotine Dependence on Relapse Rate in Izmir, Turkey. Turk J Med Sci 2015;45:895-901.

27. Lancaster T, Hajek P, Stead LF, West R, Jarvis MJ. Prevention of relapse after quitting smoking: a systematic review of trials. Arch Intern Med 2006;166:828-35.

28. Esen AD, Soylem Y, Arica S, Belgin G, Gonultas N. Factors affecting success and abstinence within a smoking cessation clinic: A one-year follow-up study in Turkey. Tob Prev Cessat 2020;6:71

29. Tonstad S, Tønnesen P, Hajek P, et al. Effect of maintenance therapy with varenicline on smoking cessation: a randomized controlled trial. JAMA 2006;296:64-71. 